\title{
Mass of piled lumber estimated through vibration test
}

\author{
Yoshitaka Kubojima ${ }^{1 *}$, Satomi Sonoda ${ }^{2}$ and Hideo Kato ${ }^{1}$
}

\begin{abstract}
The aim of this study is to propose a method for measuring the mass of wood lumber in piles through a vibration test. Air-dried sitka spruce (Picea sitchensis Carr.) pieces with 1500-1600 mm length (L), $105 \mathrm{~mm}$ width (R), and $105 \mathrm{~mm}$ thickness $(T)$ were used as specimens. We created a model of wood lumber inside a pile. A load 10 times that of the specimen was applied to the specimen, and vibration was initiated in the direction of the specimen's length. The vibration test was conducted for the specimen with, and without a small steel plate. The specimen mass was estimated without weighing using the method based on the difference of the resonance frequency when a concentrated mass is added to and subtracted from wood. The specimen mass was thus estimated accurately through this vibration method. It is possible that the mass of the water removed from the wood lumber by drying can be estimated with this vibration method.
\end{abstract}

Keywords: Additional mass, Drying, Piled wood lumber, Vibration test

\section{Introduction}

In wood drying, the moisture content of wood lumber at the end of the drying process is very important. The moisture content of the wood lumber outside of the pile can be easily determined using a commercial moisture meter. However, it is difficult to measure the moisture content of the wood lumber inside the pile; moisture meters cannot be generally attached to the cross section of the wood lumber because they are not designed to measure the cross section, and the moisture content around the end of wood lumber is too low and not representative of the whole wood lumber. Hence, it is necessary to dismantle the pile and take the wood lumber from inside the pile out for weighing. However, this process is labor-intensive and space is required to place the wood lumber when the pile is dismantled.

The mass of water that has been removed from the wood lumber due to drying can be obtained by weighing the wood lumber before and after drying. Hence, a

\footnotetext{
*Correspondence: kubojima@ffpri.affrc.go.jp

${ }^{1}$ Forestry and Forest Products Research Institute, 1 Matsunosato, Tsukuba, Ibaraki 305-8687, Japan

Full list of author information is available at the end of the article
}

weighing method for the wood lumber inside the pile is desired.

A vibration method for obtaining the mass, density, and Young's modulus without weighing based on the difference of the resonance frequency when a concentrated mass is added to and subtracted from wood has been proposed [1-12]. This method is referred to as the "Vibration method with additional mass (VAM)" in the present study.

VAM has been studied from various aspects for practical use. Since the weight of the upper lumber is applied to the lower lumber through crossers, the effect of the crossers' positions on VAM was investigated [8]. As a result, accurate density and Young's modulus values could be determined using VAM, without the influence of the weight of the upper lumber, by placing crossers at the nodal positions of the longitudinal vibration. The estimation accuracy of VAM using bending vibration was higher than that using longitudinal vibration [9]. The accurate resonance frequency for bending vibration could be generated by tapping the cross section of the wood lumber and the bending vibration with such a method was effective for VAM [10]. 
In this study, we created a model of wood lumber inside the pile. The purpose of this study is to determine whether bending vibration can be generated by tapping the cross section of the wood lumber inside the pile, and to determine whether this method for generating the bending vibration is effective to VAM.

\section{Theory}

Bending vibration under free-free condition is considered. In the case of a thin bar with a constant cross section, the effects of shear deflection and rotary inertia involved in the bending vibrational deflection are negligible, and the Euler-Bernoulli elementary theory of bending can be applied to the bending vibration.

The resonance frequency, represented by $f_{\mathrm{n} 0}$ (n: resonance mode number, 0 : value without the additional mass), is expressed as follows:

$$
f_{\mathrm{n} 0}=\frac{1}{2 \pi}\left(\frac{m_{\mathrm{n} 0}}{l}\right)^{2} \sqrt{\frac{E I}{\rho A}},
$$

where $l, E, \rho, I$, and $A$ are the specimen length, Young's modulus, density, the second moment of area, and the cross-sectional area. $m_{\mathrm{n} 0}$ is a constant that is expressed as follows:

$$
\begin{aligned}
& m_{10}=4.730, \quad m_{20}=7.853, \quad m_{30}=10.996 \\
& m_{\mathrm{n} 0}=\frac{1}{2}(2 n+1) \pi \quad(n>3) .
\end{aligned}
$$

The resonance frequency is decreased experimentally by attaching an additional mass while the dimensions, density, and Young's modulus are not altered. Hence, it can be said that $m_{\mathrm{n} 0}$ changes to $m_{\mathrm{n}}$. As a result, the resonance frequency after attaching the additional mass is expressed as follows:

$$
f_{\mathrm{n}}=\frac{1}{2 \pi}\left(\frac{m_{\mathrm{n}}}{l}\right)^{2} \sqrt{\frac{E I}{\rho A}} .
$$

From Eqs. (1) and (3),

$$
m_{\mathrm{n}}=\sqrt{\frac{f_{\mathrm{n}}}{f_{\mathrm{n} 0}}} m_{\mathrm{n} 0} .
$$

The frequency equation for the free-free vibration with concentrated mass $M$ placed at position $x=a l$ ( $x$ : distance along the bar, $0 \leq a \leq 1, a+b=1$ ) on the bar (Fig. 1) is expressed as follows:

$$
\begin{aligned}
&\left(\cos m_{\mathrm{n}} \cosh m_{\mathrm{n}}-1\right)-\frac{1}{2} \mu m_{\mathrm{n}}\left\{\left(\cos a m_{\mathrm{n}} \cosh a m_{\mathrm{n}}+1\right)\left(\sin b m_{\mathrm{n}} \cosh b m_{\mathrm{n}}-\cos b m_{\mathrm{n}} \sinh b m_{\mathrm{n}}\right)\right. \\
&\left.+\left(\cos b m_{\mathrm{n}} \cosh b m_{\mathrm{n}}+1\right)\left(\sin a m_{\mathrm{n}} \cosh a m_{\mathrm{n}}-\cos a m_{\mathrm{n}} \sinh a m_{\mathrm{n}}\right)\right\}=0,
\end{aligned}
$$




\section{Vibration test with specimen suspended by two threads}

The test bar was suspended by two threads at the nodal positions of free-free bending vibration corresponding to its first resonance mode $(0.2242 l$ and $0.7758 l)$, and then the vibration was initiated in the direction of the bar length at one end using a wooden hammer, while the bar motion was detected using a microphone (PRECISION SOUND LEVEL METER 2003, NODE Co., Ltd, Tokyo, Japan) at the same end, assuming actual sites. The direction of the microphone was vertical. The signal was processed through a fast Fourier transform (FFT) digital signal analyzer (Multi-Purpose FFT Analyzer CF-5220, Ono Sokki Co., Ltd, Yokohama, Japan) to yield high-resolution resonance frequencies (Fig. 2).

The vibration test was conducted with and without a steel plate, whose dimensions were $30 \mathrm{~mm}$ width, $10 \mathrm{~mm}$ thickness and $45 \mathrm{~mm}$ length (106 g), and we measured the resonance frequency. The steel plate was bonded at $x=0$ on the LR-plane with double-sided adhesive tape.

\section{Vibration test for the pile model}

A model was created of a pile of wood lumber. In order to reduce the contact area, each specimen was supported at the loading position, corresponding to its first resonance mode, using an iron jig with an area of $10 \mathrm{~mm}$ (L-direction of the specimen) $\times 200 \mathrm{~mm}$ (R-direction of the specimen). Two $10 \mathrm{~mm}$ (L-direction of the specimen) $\times 200 \mathrm{~mm}$ (R-direction of the specimen) $\times 5 \mathrm{~mm}$ (T-direction of the specimen) rubber sheets were inserted between each specimen and its iron jig to obtain clear waveforms (Fig. 3) [8]. The same iron jigs with the rubber sheet, a wood bar with the same dimensions as the specimens, and weights were placed on the specimen.

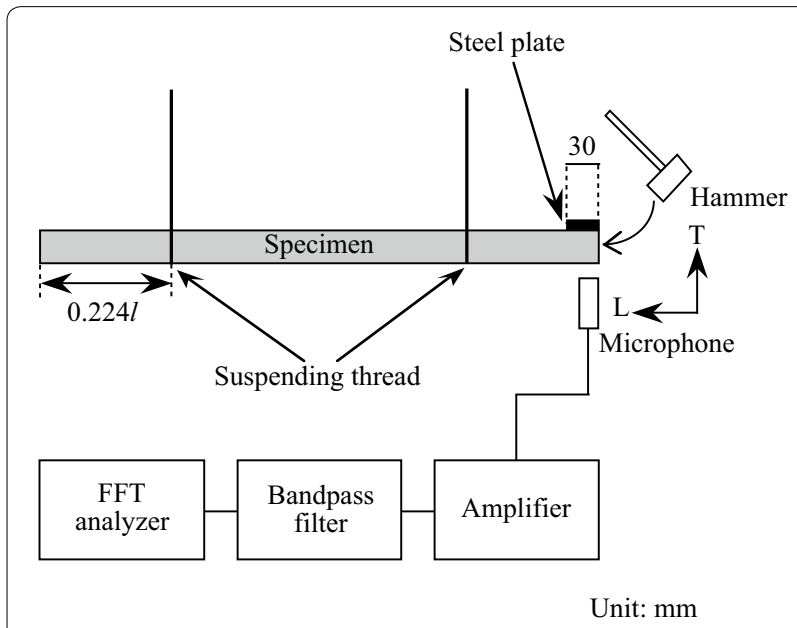

Fig. 2 Schematic diagram of the vibration test, where the specimen is suspended by two threads
The sum of the mass placed on the specimen corresponded to about ten specimens.

The vibration was initiated in the direction of the specimen's length at one end using a wooden hammer, whereas the motion of the bar was detected by the abovementioned microphone at the same end, assuming actual sites. The direction of the microphone was vertical. The signal was processed through the above-mentioned FFT digital signal analyzer to yield high-resolution resonance frequencies. The above-mentioned steel plate was used as a concentrated mass and was bonded at $x=0$ on the LRplane with double-sided adhesive tape.

\section{Results and discussion}

Figure 4 shows an example of waveforms produced during the vibration test, where the specimen is suspended by two threads (Fig. 2). Various vibration modes appeared. The Young's modulus obtained by the GoensHearmon regression method based on the Timoshenko theory of bending [13-15] using the resonance frequencies of B1-B4 was 13.24 GPa, while Young's moduli obtained based on the longitudinal vibration theory using L1, L2, L3, L4, and L5 were 13.43, 13.48, 13.50, 13.48, and $13.46 \mathrm{GPa}$, respectively. Because the values were similar, B1-B4 were the bending vibration modes and L1-L5 were the longitudinal vibration modes [10]. Thus, the bending modes could be distinguished from the longitudinal modes and the resonance frequency B1 was used for the following analysis.

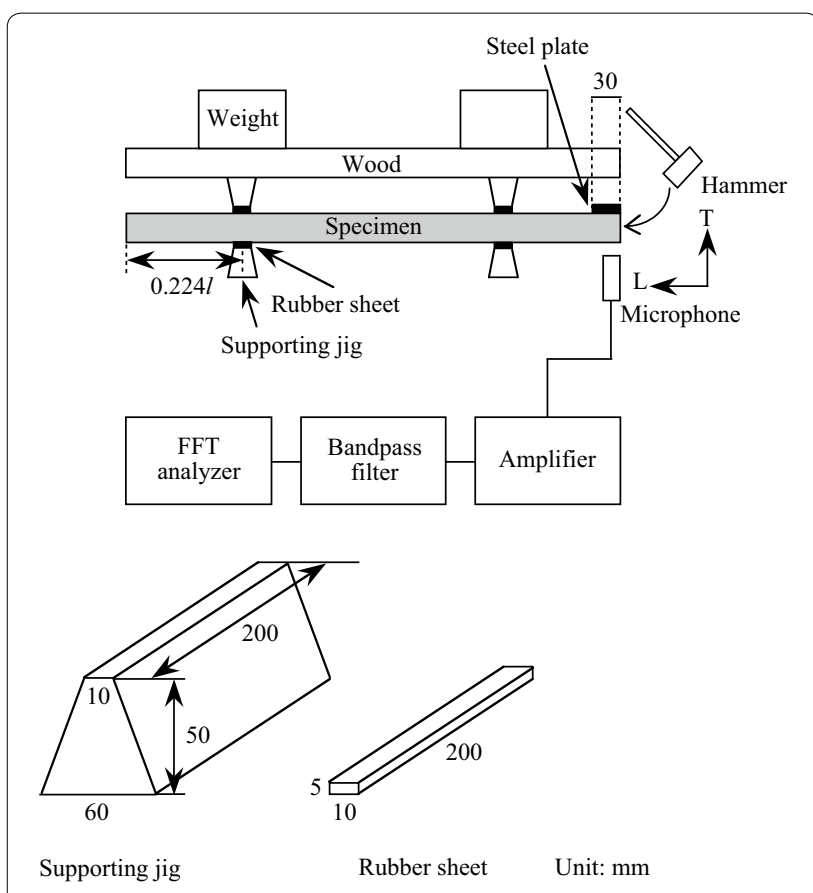

Fig. 3 Schematic diagram of the vibration test for the piled model 


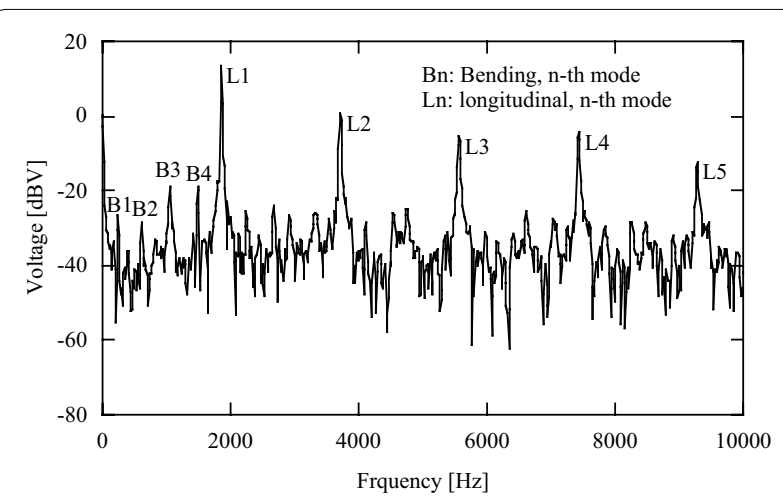

Fig. 4 An example of waveforms of vibration test, where the specimen is suspended by two threads

The estimation of the specimen mass by VAM is discussed. The estimation accuracy of VAM is expressed by the mass ratio (specimen mass estimated by VAM/ measured specimen mass). The closer this value is to 1 , the higher the estimation accuracy is. In VAM, the position of the concentrated mass was $x=0$ and the center of gravity of the concentrated mass $x_{\mathrm{G}}=30 / 2=15 \mathrm{~mm}$.

When the specimen was suspended by two threads (Fig. 2; Table 1), the estimation accuracy was higher for $x=x_{\mathrm{G}}$ than for $x=0$. This was the same tendency as the previous study [10]. The estimation accuracy for $x=x_{\mathrm{G}}$ was considered sufficiently high.
Table 2 represents the results of the piled-lumber model (Fig. 3). Comparing the resonance frequency for the piled-lumber model (Table 2) with that where the specimen was suspended by two threads (Table 1), the vibration restraint caused by the weight placed on the specimen was small. The estimation accuracy showed the same tendency in both cases. Hence, the bending vibration generated by tapping the cross section of the wood lumber, on which there is another wood lumber, could be used for VAM.

The application of this method to actual piles was considered. Although it takes time to attach and detach the concentrated mass in VAM, it is not necessary to inspect all the wood lumber in a pile using VAM. A moisture meter can be used for the wood lumber outside the pile, as mentioned above, and the inspection with VAM requires several specimens inside the pile. Therefore, the time required to attach and detach the concentrated mass is not considered a serious problem.

The microphone cannot be used at several wood drying sites due to the loud noise. A non-contact laser displacement meter or an accelerometer that also serves as a concentrated mass can be used in such cases.

In addition, the vibration restraint at the crosser is a possible problem. In practice, placing the crossers at the vibration nodes accurately may be difficult, when lumber is piled. Hence, it is necessary to consider the influence of the position of the crosser. If the specimen is long, more

Table 1 Accuracy of VAM (vibration test, where the specimen is suspended by two threads)

\begin{tabular}{|c|c|c|c|c|c|c|c|c|c|}
\hline \multirow[t]{2}{*}{ Specimen } & \multirow[t]{2}{*}{$I(\mathrm{~mm})$} & \multirow[t]{2}{*}{$M_{0}(\mathrm{~g})$} & \multirow[t]{2}{*}{$f_{10}(\mathrm{~Hz})$} & \multirow[t]{2}{*}{$M(g)$} & \multirow[t]{2}{*}{$f_{1}(\mathrm{~Hz})$} & \multicolumn{2}{|l|}{$x_{\mathrm{CM}}=0$} & \multicolumn{2}{|l|}{$x_{\mathrm{CM}}=x_{\mathrm{G}}$} \\
\hline & & & & & & $M_{\mathrm{VAM}}(\mathrm{g})$ & $M_{\mathrm{VAM}} / M_{0}$ & $M_{\text {VAM }}(g)$ & $M_{\mathrm{VAM}} / M_{0}$ \\
\hline No. 1 & 1500 & 7228.0 & 251.5000 & 106.0051 & 245.0000 & 7542.5 & 1.04 & 6823.9 & 0.94 \\
\hline No. 2 & 1500 & 6673.0 & 250.6250 & 106.0049 & 243.7500 & 7068.4 & 1.06 & 6392.9 & 0.96 \\
\hline No. 3 & 1500 & 6188.6 & 229.0625 & 106.0041 & 222.5000 & 6740.0 & 1.09 & 6094.4 & 0.98 \\
\hline No. 4 & 1599 & 7305.0 & 219.0000 & 106.0036 & 213.7500 & 8182.4 & 1.12 & 7452.7 & 1.02 \\
\hline No. 5 & 1599 & 7070.0 & 216.8750 & 106.0021 & 211.5625 & 7993.7 & 1.13 & 7280.1 & 1.03 \\
\hline
\end{tabular}

I: specimen length; $M_{0}$ : measured specimen mass; $f_{10}$ : resonance frequency of the first mode without the concentrated mass; $M$ : concentrated mass; $f_{1}$ : resonance frequency with the concentrated mass of the first mode; $x_{\mathrm{CM}}$ : position of the concentrated mass; $x_{\mathrm{G}}$ : center of gravity of the concentrated mass ( $15 \mathrm{~mm}$ from the end); $M_{\text {VAM }}$ : estimated specimen mass by VAM

Table 2 Accuracy of VAM (vibration test for the pile model)

\begin{tabular}{|c|c|c|c|c|c|c|c|c|c|c|}
\hline \multirow[t]{2}{*}{ Specimen } & \multirow[t]{2}{*}{$I(\mathrm{~mm})$} & \multirow[t]{2}{*}{$M_{0}(\mathrm{~g})$} & \multirow[t]{2}{*}{$f_{10}(\mathrm{~Hz})$} & \multirow[t]{2}{*}{$P(\mathrm{~kg})$} & \multirow[t]{2}{*}{$M(g)$} & \multirow[t]{2}{*}{$f_{1}(\mathrm{~Hz})$} & \multicolumn{2}{|l|}{$x_{\mathrm{CM}}=0$} & \multicolumn{2}{|c|}{$x_{\mathrm{CM}}=x_{\mathrm{G}}$} \\
\hline & & & & & & & $M_{\text {VAM }}(\mathrm{g})$ & $M_{\mathrm{VAM}} / M_{0}$ & $M(g)$ & $M_{\mathrm{VAM}} / M_{0}$ \\
\hline No. 1 & 1500 & 7228.0 & 255.0000 & 73.22 & 106.0031 & 248.3750 & 7499.6 & 1.04 & 6785.0 & 0.94 \\
\hline No. 2 & 1500 & 6673.0 & 252.9375 & 73.78 & 106.0016 & 245.8125 & 6866.0 & 1.03 & 6208.9 & 0.93 \\
\hline No. 3 & 1500 & 6188.6 & 232.8125 & 73.78 & 106.0013 & 226.3750 & 7006.8 & 1.13 & 6337.0 & 1.02 \\
\hline No. 4 & 1599 & 7305.0 & 220.7500 & 73.62 & 106.0013 & 215.5000 & 8252.9 & 1.13 & 7517.1 & 1.03 \\
\hline No. 5 & 1599 & 7070.0 & 218.8500 & 73.86 & 106.0011 & 213.7500 & 8435.8 & 1.19 & 7684.5 & 1.09 \\
\hline
\end{tabular}

I and $M_{0}$ are same values as Table 1.P: sum of the iron jigs with a rubber sheet, wood with the same dimensions as the specimens, and weights placed on the specimen. Refer to Table 1 
than two crossers will be required, so it is necessary to consider the effect of the number of crossers. Since the vibration node has no width, theoretically, the contact area between the support and the specimen was reduced (10 $\mathrm{mm}$ in the length direction of the specimen, Fig. 3) to approach the ideal condition in this study. It is necessary to consider the width of the crosser in practical applications. Furthermore, it is necessary to examine whether there is a more appropriate material for the crosser, other than the rubber used in this study.

\section{Conclusions}

VAM was applied to wood lumber in the piled-lumber model and the specimen mass was estimated. The results were as follows:

1. The estimation accuracy of VAM was thought to be sufficiently high when the position of the concentrated mass in calculation was the center of gravity.

2. It is possible that the mass of the water that is removed from the wood lumber by drying can be obtained without weighing the wood lumber, because VAM could be applied to the piled-lumber model.

3. The time required to attach and detach the concentrated mass in VAM is not considered a serious problem, because VAM needs to be performed on some wood lumber in the pile.

\section{Abbreviations \\ VAM: Vibration method with additional mass; L: Longitudinal direction; R: Radial direction; T: Tangential direction; FFT: Fast Fourier transform.}

\section{Acknowledgements}

This study was supported by JSPS KAKENHI Grant number JP15K07522.

\section{Authors' contributions}

All authors designed the experiments. YK performed the experiments, analyzed the data, and was a major contributor in writing the manuscript. All authors contributed to interpretation and discussed results. All authors read and approved the final manuscript.

\section{Funding}

This study was supported by JSPS KAKENHI Grant number JP15K07522.

\section{Availability of data and materials}

All data generated or analyzed during this study are included in this published article.

\section{Competing interests}

The authors declare that they have no competing interests.

\section{Author details}

1 Forestry and Forest Products Research Institute, 1 Matsunosato, Tsukuba, Ibaraki 305-8687, Japan. ${ }^{2}$ Toyama Prefectural Agricultural, Forestry \& Fisheries Research Center, 4940 Kurokawa Shin, Imizu, Toyama 939-0311, Japan.

Received: 18 February 2020 Accepted: 24 April 2020

Published online: 11 May 2020

\section{References}

1. Skrinar M (2002) On elastic beams parameter identification using eigenfrequencies changes and the method of added mass. Comput Mater Sci 25:207-217

2. Türker T, Bayraktar A (2008) Structural parameter identification of fixed end beams by inverse method using measured natural frequencies. Shock Vib 15:505-515

3. Kubojima Y, Sonoda S (2015) Measuring Young's modulus of a wooden bar using longitudinal vibration without measuring its weight. Eur J Wood Wood Prod 73:399-401

4. Matsubara M, Aono A, Kawamura S (2015) Experimental identification of structural properties of elastic beam with homogeneous and uniform cross section. Trans JSME. https://doi.org/10.1299/transjsme.15-00279

5. Kubojima Y, Kato H, Tonosaki M, Sonoda S (2016) Measuring Young's modulus of a wooden bar using flexural vibration without measuring its weight. BioResources 11:800-810

6. Matsubara M, Aono A, Ise T, Kawamura S (2016) Study on identification method of line density of the elastic beam under unknown boundary conditions. Trans JSME. https://doi.org/10.1299/transjsme.15-00669

7. Sonoda S, Kubojima Y, Kato H (2016) Practical techniques for the vibration method with additional mass part 2: experimental study on the additional mass in longitudinal vibration test for timber measurement. In: CD-ROM proceedings of the world conference on timber engineering (WCTE 2016)

8. Kubojima Y, Sonoda S, Kato H (2017) Practical techniques for the vibration method with additional mass: effect of crossers' position in longitudinal vibration. J Wood Sci 63:147-153

9. Kubojima Y, Sonoda S, Kato H (2017) Practical techniques for the vibration method with additional mass: effect of specimen moisture content. J Wood Sci 63:568-574

10. Kubojima Y, Sonoda S, Kato H (2018) Practical techniques for the vibration method with additional mass: bending vibration generated by tapping cross section. J Wood Sci 64:16-22

11. Kubojima Y, Sonoda S, Kato H (2018) Application of the vibration method with additional mass to timber guardrail beams. J Wood Sci 64:767-775

12. Kubojima Y, Sonoda S, Kato H (2019) Use of cut specimen pieces in the vibration method with additional mass (VAM). J Wood Sci 65:30

13. Timoshenko SP (1921) On the correction for shear of the differential equation for transverse vibrations of prismatic bars. Phil Mag 6 Ser 41:744-746

14. Goens E (1930) Über die Bestimmung des Elastizitätsmodulus von Stäben mit Hilfe von Biegungsschwingungen. Ann Phys 5:649-678 (in German)

15. Hearmon RFS (1958) The influence of shear and rotatory inertia on the free flexural vibration of wooden beams. Br J Appl Phys 9:381-388

\section{Publisher's Note}

Springer Nature remains neutral with regard to jurisdictional claims in published maps and institutional affiliations.

\section{Submit your manuscript to a SpringerOpen ${ }^{\circ}$ journal and benefit from:}

- Convenient online submission

- Rigorous peer review

- Open access: articles freely available online

- High visibility within the field

- Retaining the copyright to your article

Submit your next manuscript at $\boldsymbol{\nabla}$ springeropen.com 